\title{
"A gente fica até sem saber o que falar do nosso CREF". Atribuições e ações do sistema CONFEF/CREFs na perspectiva de docentes de graduação de Porto Velho, Rondônia
}

\section{RESUMO}

A regulamentação da profissão da Educação Física (EDF) deu-se pela Lei Federal $\mathrm{n}^{\mathbf{0}}$ 9.696/98, através da qual foi criado o Conselho Federal (CONFEF) e os Conselhos Regionais de Educação Física (CREFs). A presente pesquisa, caracterizada como exploratória e descritiva, teve como objetivo explorar e discutir as percepções de docentes de cursos de graduação em EDF de Porto Velho a respeito das atribuições e ações do sistema CONFEF/CREFs. Catorze docentes de cursos de graduação em EDF de duas Instituições de Ensino Superior (IES) privadas foram entrevistados. Conjuntamente, as análises revelam que os docentes são conhecedores de grande parte das atribuições e competências do sistema CONFEF/CREFs. Todavia, no que diz respeito ao cumprimento dessas, todos os docentes consideram que o sistema revela-se falho, especialmente na fiscalização dos profissionais, na divulgação de suas ações, bem como na valorização, representação e defesa da profissão perante a sociedade.

PALAVRAS-CHAVE: CONFEF/CREFs; Educação física; Docentes

\section{Gigliane Pereira da Silva Marques Cordeiro}

Graduanda

Universidade Federal de Rondônia - UFRO, Porto Velho, Rondônia, Brasil gygliane@gmail.com

https://orcid.org/0000-0002-5545-331X

\section{Daniela Cândido Oliveira}

Especialista

Universidade Federal de Rondônia - UFRO,

Porto Velho, Rondônia, Brasil

danyelacandido@bol.com.br

[ttps://orcid.org/0000-0002-1500-4755

Daniel Delani

Doutor

Universidade Federal de Rondônia - UFRO,

Porto Velho, Rondônia, Brasil danieldelani@unir.br

'htps://orcid.org/0000-0002-2470-6302

Silvia Teixeira de Pinho

Doutora

Universidade Federal de Rondônia - UFRO,

Porto Velho, Rondônia, Brasil silvia@unir.br

${ }^{\circledR}$ https://orcid.org/0000-0002-7805-5146

Tatiane Gomes Teixeira

Doutora

Universidade Federal de Rondônia - UFRO,

Porto Velho, Rondônia, Brasil

tatiane.teixeira@unir.br

https://orcid.org/0000-0003-4337-040X 
"We do not even know what to say about our CREF". Attributions and actions of the CONFEF/CREFs system from the perspective of undergraduate teachers in Porto Velho, Rondônia

\begin{abstract}
Regulation of the Physical Education (PE) profession was given by Federal Law No. 9,696/98, through which the Federal Council (CONFEF) and the Regional Physical Education Councils (CREFs) were created. This study, characterized as exploratory and descriptive, aimed to explore and discuss the perceptions of undergraduate PE course teachers in Porto Velho regarding the attributions and actions of the CONFEF/CREF system. Fourteen undergraduate PE course teachers from two private Higher Education Institutions (HEI) were interviewed. Together, the analyzes reveal that the teachers are familiar with most of the attributions and competencies of the CONFEF/CREF system. However, with regard to the fulfillment of these, all undergraduate teachers consider the system to be flawed, especially in the inspection of professionals, in the disclosure of their actions, as well as in the valorization, representation and defense of the profession before society.
\end{abstract}

KEYWORDS: CONFEF/CREFs; Physical education; University professors

"La gente se queda hasta no saber qué hablar de nuestro CREF". Atribuciones y acciones del sistema CONFEF/CREFs en perspectiva de docentes de graduación de Porto Velho, Rondônia

\title{
RESUMEN
}

La regulación de laprofesión de EducaciónFisica (EF) en Brasil fue dada por laley Federal 9696/98, a través de lacual se crearonelConsejo Federal (CONFEF) y losconsejosRegionales (CREFs). La presente investigación, caracterizada como exploratoria y descriptiva, tuvo como objetivo explorar y discutir las percepciones de docentes de curso de graduaciónen EF enlaciudad de Porto Velho conrespecto a lasatribuciones y accionesdel sistema CONFEF/CREFs. Se entrevistó a catorce docentes de cursos de graduaciónen EF de dos instituciones privadas de nivel superior. Los análisisrevelan que los docentes conocenlamayoría de lasatribuciones y competenciasdel sistema. Conrespectoalcumplimiento de estos, todos losprofesoresconsideran que el sistema tiene problemas, especialmente enlainspección de profesionales, enladivulgación de sus acciones, así como enlavalorización, representación y defensa de laprofesión ante lasociedad.

PALABRAS-CLAVE: CONFEF/CREFs; Educación física; Docentes 


\section{INTRODUÇÃO}

A Educação Física (EDF) é uma área de atuação profissional historicamente permeada por embates e lutas em busca de reconhecimento perante a sociedade. Em 1998 a profissão foi regulamentada pela lei 9.696 (BRASIL, 1998), a qual criou o Conselho Federal (CONFEF) e os Conselhos Regionais de Educação Física (CREF's), atualmente organizados como sistema CONFEF/CREFs (CONFEF, 2010).

Na visão de Reppold Filho (2003), a regulamentação da profissão foi muito importante para sociedade, porque a partir dela apenas indivíduos credenciados poderiam trabalhar orientando e acompanhando a prática de exercícios físicos. Desta forma, em função da definição das prerrogativas do profissional de EDF, foi possível estabelecer parâmetros éticos para a profissão. $\mathrm{Na}$ mesma perspectiva, estudando a realidade de Minas Gerais, Oliveira (2017), considera que os profissionais de EDF e também a sociedade demonstraram mudanças de atitude quando a profissão foi regulamentada.

Embora a regulamentação da profissão possa ser considerada uma importante conquista da classe, é vasta a literatura crítica a esta e ao sistema CONFEF/CREFs (GUIATA; SILVA, 2008; SOBRINHO et al., 2011; SILVA; FRIZZO, 2011; DE PAULA; SILVA, 2014; NEIRA; BORGES, 2018). Em conjunto, as publicações evidenciam que as ações do CONFEF/CREFs não encontram aceitação e aprovação por parte importante de pesquisadores da área. Essa ausência de consensualidade do processo de regulamentação de uma profissão, entretanto, é entendida como algo característico desse processo (ALMEIDA; MONTAGNER; GUTIERREZ, 2009).

Na visão de Tojal (2001), o CONFEF e os CREFs, pelas suas atribuições em lei, devem atuar fundamentalmente no compromisso de uma EDF de qualidade. Assim, devem intervir em prol da melhoria e valorização de seus profissionais, cumprindo o código de ética estabelecido, complementando sua intervenção com ações vigorosas e consistentes, de forma que a EDF possa alcançar a qualidade objetivada e assim contribuir para uma sociedade cada vez melhor.

Embora a perspectiva de Tojal pareça animadora, Silva e Landin (2003), consideram que, na prática, o conselho de classe da EDF não colabora com a classe trabalhadora e tampouco se preocupa com a qualidade da sua formação. Portanto, discutir o sistema CONFEF/CREFs é considerado assunto polêmico e cercado de dificuldades no âmbito da ciência (ALMEIDA; MONTAGNER; GUTIERREZ, 2009).

Se de um lado, inúmeros autores manifestam-se contrários ao CONFEF/CREFs, faltam pesquisas sobre como os atores diretamente participantes deste cenário (profissionais) percebem tal 
sistema. Cotidianamente é comum encontrar, tanto entre profissionais inseridos no mercado de trabalho (LOPES et al., 2020), quanto nas Instituições de Ensino Superior -IES (PEREIRA et al., 2018), relatos de descontentamento e insatisfação, inclusive com o sistema CONFEF/CREFs (MENDES, 2014). Dificuldades de parte dos profissionais em compreender e explicar de forma clara o papel e as ações deste sistema também são observáveis.

A realidade apresentada contribui para um distanciamento entre a classe profissional e seu conselho. Desta forma, entende-se como essencial para o fortalecimento da profissão de EDF, compreender como os profissionais formadores (docentes de IES), percebem seu conselho de classe, em relação as suas atribuições e o seu papel na sociedade. Na literatura disponível não há trabalhos que investigam esse assunto. A presente pesquisa está ancorada neste contexto e explora a realidade da cidade de Porto Velho.

Porto Velho é a capital do Estado de Rondônia. Nesta cidade o sistema CONFEF/CREFs é representado por uma seccional do $\mathrm{CREF} / 8$. Além de Rondônia, este CREF é responsável pelos estados do Amazonas, Acre e Roraima. Sua sede encontra-se localizada em Manaus e há uma seccional local em cada um dos Estados compreendidos. A seccional CREF/RO foi criada pela Resolução No 34/2001 e, em Rondônia, dispõe de apenas uma equipe para atender os 52 municípios do Estado (CREF8, 2020).

Diante do exposto, o presente estudo teve como objetivo explorar as percepções de professores de cursos de graduação em EDF, na cidade de Porto Velho, a respeito do Sistema $\mathrm{CREF} / \mathrm{CONFEF}$, no que diz respeito às atribuições e ações dessa instituição. As percepções dos docentes foram analisadas e discutidas à luz do Estatuto do CONFEF, publicado há dez anos (CONFEF, 2010). Este documento apresenta todas as finalidades, competências e atribuições específicas do CONFEF e CREFs, órgãos estes "de normatização, disciplina, defesa e fiscalização dos profissionais de EDF, em prol da sociedade" (CONFEF, 2010).

\section{MATERIAIS E MÉTODOS}

A pesquisa teve natureza exploratória e descritiva, preocupando-se com a compreensão, apresentação e discussão das percepções de docentes de cursos de graduação em EDF, a respeito de um tema pouco abordado: atribuições e ações do sistema CONFEF/CREFs. Possui, portanto, abordagem qualitativa, já que foi realizada para compreender o universo das percepções humanas, valorizando as perspectivas de cada participante e buscando considerar o contexto em que as respectivas falas foram geradas.

Foram entrevistados 14 professores atuantes em curso de graduação em EDF. O contato e convite desses à participação na pesquisa foi realizado nas duas IES privadas que ofertam o curso 
em questão na cidade de Porto Velho. A maioria dos entrevistados era homem (n=8); e o total de dez dos docentes tinham graduação do tipo licenciatura plena. O tempo de conclusão do curso de graduação variou entre 2 e 33 anos. Em relação ao maior grau de pós-graduação, nove entrevistados tinham especialização, quatro eram mestres e um tinha doutorado. A maioria dos docentes concluiu sua graduação na Região Norte ( $\mathrm{n}=12)$, mais especificamente na Universidade Federal de Rondônia $(n=9)$.

As entrevistas foram do tipo semiestruturadas e realizadas durante o primeiro trimestre de 2019. Foram conduzidas individualmente, em local reservado, sendo gravadas através de smartphone, utilizando o aplicativo "Gravador de Voz". Os áudios das entrevistas foram transcritos em texto para realização da análise de conteúdo. Esta foi do tipo temática, consistindo, portanto, no processo de descoberta e organização dos núcleos de sentido presentes nas falas (MINAYO, 2008)

À primeira leitura, em cada entrevista foram identificadas as atribuições e ações percebidas pelo(a) docente. Para tanto, foram observados os conteúdos e sentidos manifesto e implícito presentes nas falas. Em seguida, por similaridade dos conteúdos identificados, as categorias de atribuições e ações do sistema CONFEF/CREFs percebidos pelos docentes foram definidos. Finalizada esta etapa, cada entrevista foi novamente analisada, buscando verificar se todas as falas estavam adequadamente contempladas e se haviam sido alocadas na categoria pertinente. Na última etapa da análise, com o intuito de viabilizar a apresentação dos resultados e discussão, as categorias foram organizadas em grupos. Tal aspecto foi necessário pela quantidade relevante de categorias e do objetivo do estudo de descrever todas as atribuições e ações elencadas pelo grupo pesquisado.

A pesquisa faz parte do projeto intitulado Formação e atuação profissional na área de Educação Física, aprovado pelo Comitê de ética em pesquisa (CEP) sob CAAE 66590.617.0.0000.5300 e parecer n 2.307.443. Atendeu as Resoluções 466/2012 e 510/2016 do Conselho Nacional de Saúde. Todos os participantes assinaram Termo de Consentimento Livre e Esclarecido. A fim de preservar a identidade dos entrevistados, nomes fictícios foram utilizados na apresentação das falas, especificamente na seção resultados e discussão.

\section{RESULTADOS E DISCUSSÃO}

A presente pesquisa teve como objetivo explorar as percepções de docentes de graduação em EDF da cidade de Porto Velho, acerca das atribuições e ações do sistema CONFEF/CREFs. Aquelas elencadas pelos docentes foram organizadas em três grupos e constam detalhadamente na Tabela 1. No grupo 1 foram incluídas as respostas que indicam ações do sistema CONFEF/CREFs necessárias para cumprir sua função de regulamentação, organização ou fiscalização. $O$ grupo 2 foi denominado valorizar, representar e defender a EDF perante a sociedade. Nesta sessão, foram 
incluídas as atribuições e ações relacionadas à busca pelo aumento do status social da área. Já o grupo 3, denominado apoiar, auxiliar e orientar o profissional de EDF e as IES formadoras, apresenta as respostas que se referem às ações que impactam diretamente o profissional.

Conforme pode ser também observado na Tabela 1, a última coluna apresenta o número de docentes insatisfeitos com o conselho de classe em algum aspecto relacionado às atribuições e/ou ações desse sistema. Embora não estivesse no objetivo inicial da pesquisa investigar os aspectos de insatisfação, dois fatores levaram à inclusão deste tema na pesquisa: o pequeno número de ações efetivas relatadas e o fato de todos os docentes se declararem insatisfeitos com o sistema CONFEF/CREFs, em um ou mais aspectos. Somente seis tipos de ações foram citadas, enquanto onze aspectos de insatisfação foram identificados nas falas. Assim, mais que as ações realizadas pelo sistema CONFEF/CREFs, o que se destacou nas entrevistas foi a insatisfação dos docentes.

Tabela 1 - Atribuições, ações e aspectos causadores de insatisfação com o Sistema CONFEF/CREFs entre docentes de graduação em Educação Física

\begin{tabular}{|c|c|c|c|}
\hline \multirow[b]{2}{*}{ Categorias de atribuições ou ações } & \multicolumn{2}{|c|}{$\begin{array}{l}\mathrm{N}^{\circ} \text { de docentes que } \\
\text { elencaram esta como }\end{array}$} & \multirow{2}{*}{$\begin{array}{c}\mathrm{N}^{\mathrm{o}} \text { de } \\
\text { docentes } \\
\text { insatisfeito } \\
\text { s com este } \\
\text { aspecto }\end{array}$} \\
\hline & $\begin{array}{l}\text { Atribuiçã } \\
\text { o }\end{array}$ & $\begin{array}{c}\text { Ação } \\
\text { realizad } \\
\text { a }\end{array}$ & \\
\hline \multicolumn{4}{|c|}{ Grupo: Regulamentar, organizar e fiscalizar } \\
\hline Fiscalização & 14 & 8 & 8 \\
\hline Regulamentação ou organização da profissão & 5 & - & - \\
\hline Registro do profissional e garantia dos seus direitos de atuação & 5 & 2 & - \\
\hline Resolução de questões administrativas dos profissionais & - & 1 & 1 \\
\hline Fazer a gestão adequada do Sistema CONFEF/CREFs & 1 & - & - \\
\hline $\begin{array}{l}\text { Verificar se os estabelecimentos estão em condições de atender os } \\
\text { clientes }\end{array}$ & 1 & - & - \\
\hline \multicolumn{4}{|c|}{ Grupo: Valorizar, representar e defender perante a sociedade } \\
\hline Colaborar para a valorização e o reconhecimento do profissional & 4 & - & - \\
\hline Lutar, defender/proteger a classe e a profissão & 4 & - & 3 \\
\hline $\begin{array}{l}\text { Representar a classe ou se fazer presente perante a sociedade e as } \\
\text { instituições }\end{array}$ & 4 & - & 3 \\
\hline Divulgação da profissão e do Sistema perante a sociedade & 2 & - & - \\
\hline \multicolumn{4}{|c|}{ Grupo: Apoiar, auxiliar e orientar o profissional e as IES formadoras } \\
\hline $\begin{array}{l}\text { Promover cursos, congressos e afins ou articular-se com } \\
\text { instituições que o fazem (capacitação profissional continuada) }\end{array}$ & 10 & 8 & 5 \\
\hline $\begin{array}{l}\text { Ser parceiro das IES, colaborando com o processo de formação e } \\
\text { orientação do futuro profissional }\end{array}$ & 5 & - & 4 \\
\hline Auxiliar o profissional, prestando orientação quando solicitado & 4 & - & 2 \\
\hline Divulgar aos profissionais as ações do conselho & - & 4 & 6 \\
\hline Colaborar para boas condições de trabalho do profissional & 3 & - & 1 \\
\hline $\begin{array}{l}\text { Fazer parceiras/convênios (com empresas locais), para beneficiar } \\
\text { o profissional }\end{array}$ & 1 & - & 3 \\
\hline $\begin{array}{l}\text { Facilitação de comunicação entre profissional de RO e CREF } \\
\text { Manaus }\end{array}$ & - & 1 & 2 \\
\hline
\end{tabular}




\section{Grupo 1: Regulamentar, organizar e fiscalizar}

A fiscalização foi a única atribuição citada por todos os docentes participantes da pesquisa. Este resultado é compreensível, visto que a fiscalização é entendida como atividade central para a qual o sistema CONFEF/CREFs existe. De fato, este sistema ressalta seu papel de agente fiscalizador (STEINHILBER, 2006). As ações de fiscalização, realizadas em todo Brasil, são amplamente divulgadas em seus informativos/boletins, instrumentos enviados mensalmente por email aos profissionais de EDF. Dessa forma, a maior visibilidade da fiscalização, em comparação às demais atribuições, assim como sua importância para a existência de um conselho de classe, são provavelmente as justificativas desse resultado.

Interessantemente, ao analisarmos o Estatuto do CONFEF, a finalidade fiscalizatória se apresenta de forma repetida desde o primeiro capítulo do documento. A seguir consta a fala de uma das entrevistadas que exemplifica o entendimento e reconhecimento coletivo que a função primordial do conselho é a fiscalização:

Ele (sistema CONFEF/CREFs) fiscaliza o exercício do profissional. É o órgão fiscalizador. E eu acho que não é só isso. Além de ser um órgão fiscalizador, ele também é aquele órgão que o profissional pode ir para buscar um auxílio, para buscar uma informação. Agora, ultimamente, também está disponibilizando algumas formações, alguns aperfeiçoamentos (Bianca).

Ao mesmo tempo em que menciona a fiscalização, a docente manifesta entendimento de que as competências do sistema CONFEF/CREFs vão além de fiscalizar e reconhece a realização de eventos e cursos que beneficiam o profissional - assunto que será abordado na terceira sessão desses resultados.

Interessantemente, a fiscalização é ao mesmo tempo a atribuição mais conhecida e o aspecto com o qual o maior número de docentes $(n=8)$ relatou algum grau de insatisfação. Os aspectos destacados por esses foram: permite que licenciado atue fora do ambiente escolar $(n=5)$, permite que leigos atuem na $\operatorname{EDF}(n=4)$, não fiscaliza ou fiscaliza muito pouco $(n=3)$, desequilíbrio na físcalização, ou seja, fiscaliza alguns tipos de estabelecimento e outros não $(n=2)$, constrange o profissional durante fiscalização ou não lida adequadamente durante esta $(n=2)$, fiscalização em áreas nas quais é permitido atuar sem graduação em EDF $(n=1)$ e há incoerência, em alguns momentos é de uma forma e depois muda $(n=1)$. Algumas falas exemplificadoras deste resultado constam a seguir:

É um sistema bom, que funciona. O único problema da região, que eu acho, principalmente aqui da cidade, é em relação à fiscalização, entende? A gente tem muito problema de profissional que não está apto e atuando. Aí de uma forma até 
antiética ou até, como eu posso dizer, contra lei. Porque tem desde acadêmico atuando sem a formação ainda, como pessoas que nem sequer estudam, que nem tem graduação e estão atuando, principalmente na área de personaltrainer, atendimento personalizado (Lucas).

Em relação à fiscalização, a atuação do CREF, eu não acho que eles fazem de uma maneira que seja interessante para a classe. Principalmente, aquela que realmente atua como profissional, que paga a carteira do CREF. Deve ser realmente um trabalho muito difícil para o conselho regional de educação física, o CONFEF em si, para poder fiscalizar. Mas eu acho que eles deveriam montar uma estratégia melhor, justamente porque, se regulamentaram uma profissão, seria interessante que cuidassem dessa parte para que outras pessoas não pudessem atuar como profissional de educação física, sendo que elas não são (Daiane).

$\mathrm{Na}$ verdade, eu até daria uma sugestão pra eles, deles não chegarem tão incisivos. Eu sei que é fiscal, mas eu acredito que não precisa chegar assim: chegar, chegando. Parece que eles chegam nessa forma e, aparentemente, passam que não sabem das leis. Eles querem apenas ir multando ou, enfim, fazendo algo que não deveriam. Acredito que eles precisam ter esse domínio maior com o público (Neide).

As falas anteriores exemplificam a insatisfação manifestada com a fiscalização. É importante ressaltar que nenhum dos entrevistados se mostrou contrário à regulamentação da profissão, questão esta bastante debatida em pesquisas prévias (SILVA; FRIZZO, 2011).

Após a fiscalização, o registro profissional e garantia dos seus direitos de atuação $(n=5)$ e regulamentar e/ou organizar a profissão foram as atribuições mais citadas dentro do grupo 1 .

Historicamente, a EDF é uma área que enfrentou diversos problemas (LOPES, 2016). Acreditava-se, por exemplo, que o fato de muitos profissionais não terem formação específica em educação para ensinar e monitorar atividades físicas, fazia com que a qualidade das suas aulas fosse ruim (ALMEIDA; MONTAGNER; GUTIERREZ, 2009). Nesse sentido, a regulamentação/legitimação da profissão foi vista como algo importante, especialmente pelo entendimento que regulamentar é o caminho necessário para ampliar a valorização dessa classe profissional perante a sociedade (ALMEIDA; MONTAGNER; GUTIERREZ, 2009; OLIVEIRA, 2017).

Um dos entrevistados manifestou claramente ver de forma positiva a regulamentação. Todavia, revela-se igualmente insatisfeito com a atuação desse órgão:

Gosto da ideia de ter um conselho regimentando a nossa profissão. Entretanto, eu percebo uma falta de vontade, não sei se política, mas uma falta de atuação onde deveria ser. Eu sinto muita falta de atuação do CREF em alguns momentos (Talita).

Além das atribuições ou ações já mencionadas, destaca-se nessa sessão fazer a gestão adequada do sistema CONFEF/CREFs - seus recursos institucionais - $(n=1)$, verificar se os estabelecimentos estão em condições de atender seus clientes $(n=1)$ e resolução de questões 
administrativas dos profissionais $(\mathrm{n}=1)$. Sobre esse último aspecto, inclusive, destaca-se a insatisfação relatada por um dos docentes entrevistados. A fala a seguir exemplifica a morosidade encontrada no âmbito do sistema.

Eu trabalho numa instituição, [...] na SEJUCEL. Nós realizamos os jogos intermunicipais de Rondônia, onde são 15 modalidades. [...] Nós fizemos uma consulta ao CREF em 2017 [...]. Desde 2017 eles mandaram para o jurídico em Manaus e até agora não tivemos resposta (Eric).

É importante destacar que, apesar das insatisfações registradas ao longo das entrevistas, seis docentes mostraram-se cientes em relação às dificuldades que acreditam ou sabem existir no CREF local. O fato de a sede ser em Manaus, a falta de recursos materiais e humanos foram citados, por exemplo. Através de suas falas, revelam que não são contrários ao sistema CONFEF/CREFs, estão apenas certos de que na seccional local do CREF, embora realmente não tenha as condições ótimas para cumprir suas atribuições adequadamente, poderia fazê-lo de forma mais eficiente.

Para encerrar essa sessão, importante salientar que a análise do desempenho, eficácia e eficiência dos CREFs é, de acordo com o Estatuto, competência do CONFEF. Entretanto, quanto ao CONFEF, não há clareza acerca de quem o fiscaliza na prática de suas ações legais e atribuições regimentais.

\section{Grupo 2: Valorizar, representar e defender a profissão e os profissionais perante a sociedade}

No segundo grupo foram incluídas as categorias de falas que retratam as atribuições e ações do sistema CONFEF/CREFs, no sentido de ampliar o status social da EDF. Compreendem neste grupo: colaborar para valorização e o reconhecimento do profissional $(n=4)$, a luta e defesa da profissão e dos profissionais $(n=4)$, a atuação como representante da classe $(n=4)$ e a divulgação da profissão e ações em geral, realizadas no sentido de colaborar para que a sociedade valorize e reconheça esta área $(\mathrm{n}=2)$.

Nessa sessão, foi possível identificar a expectativa que os docentes das IES manifestam acerca de um órgão que não apenas fiscalize a classe profissional, mas também sirva de referência, apoio e legitimação de suas ações. No Estatuto do CONFEF, consta que este e os CREFs são órgãos de defesa dos profissionais de EDF. No mesmo documento, consta também nas atribuições de ambos os órgãos "zelar pela dignidade, independência, prerrogativas e valorização da profissão de Educação Física e de seus profissionais" (Art. 26; item IV).

No processo de categorização "divulgação da profissão" compreendeu as falas que retratavam a expectativa dos docentes que o sistema CONFEF/CREFs divulgue (dê publicidade) a importância da profissão ou do profissional de EDF para sociedade. Já a categoria "lutar 
defender/proteger a área de EDF" (profissão e profissional), descreve a expectativa de que o órgão busque/colabore com instâncias do poder público brasileiro (Judiciário, Executivo e Legislativo), na garantia de seus diretos e na ampliação de seus campos de atuação/intervenção. Na mesma linha de pensamento, quatro docentes entendem que se fazer presente e/ou representar a classe é importante competência do conselho.

Portanto, foi possível identificar nas entrevistas, o entendimento de que é atribuição do sistema CONFEF/CREFs trabalhar para que o profissional de EDF seja reconhecido e respeitado socialmente (valorização profissional). Todavia, a percepção comum é que esse não tem sido satisfatoriamente cumprido e que o conselho se omite diante de situações em que deveria lutar pela classe. As falas apresentadas a seguir exemplificam essa situação:

[...] Eu a vi (representante da seccional do CREF8 em Porto Velho), depois que ele faleceu (coordenador anterior da seccional CREF8 em Porto Velho), uma vez participando do conselho (Conselho Estadual de Desporto e Lazer - CONEDEL), ou seja, nem no conselho estadual, que é obrigação do CREF estar presente uma vez por mês, ela não está, nem manda representante. Então a gente não tem atuação nenhuma do CREF, eu não vejo (Eric).

Eu acho que o Conselho Federal de Educação Física, ele tinha que atuar na proteção da nossa profissão, do profissional como todo, na atualização, na capacitação dos profissionais e na melhor visualização da profissão diante da sociedade (Emiliane).

[...] Tudo que acontece em relação ao movimento humano, que é área da educação física, o CREF tem que estar presente, que seja para fiscalizar, que seja para participar com um executante, como parceiro e parceria, mas ele tem que estar porque é o órgão fiscalizador. Então ele tem a obrigação de estar presente (Tobias).

Nós temos um problema em relação às escolas, que diminuíram a quantidade de aulas. O CONFEF e CREF deveriam lutar por isso, para essa valorização, até porque é importante a educação física escolar (Daiane).

A educação infantil está sob responsabilidade do município e o município tirou os professores de educação física da escola, coisa que eu não concordo [...]. Então eu vejo uma falta de atuação do conselho, eu vejo muito o conselho querendo fechar academia, muito voltado para área do bacharelado, e esqueceu um pouco da escola. [...] Eu fico muito decepcionada com o conselho nesse sentido (Talita).

Na seccional Rondônia do CREF ocorreu uma mudança na coordenação em maio de 2017, decorrente do falecimento do então coordenador. Após essa alteração na gestão local, à ausência dos representantes do sistema CONFEF/CREFs em instâncias política-deliberativas e administrativas do poder público, como o Conselho Estadual de Desporto e Lazer (CONEDEL), em Rondônia, causa desconforto e descontentamento aos profissionais de EDF na região. Evidencia o baixo envolvimento desse órgão na tomada de decisões do poder público, algumas dessas, que impactam diretamente a atuação do profissional de EDF e o seu mercado de trabalho, como ocorreu 
com implantação das Diretrizes Curriculares Nacionais para o Ensino Fundamental de nove anos (BRASIL, 2010), que permitiu aos pedagogos atuarem nas aulas de EDF do $1^{\circ}$ ao $5^{\circ}$ ano e também contribuiu para diminuição do número de aulas desse componente curricular na escola, impactando o pleno desenvolvimento das crianças nessa fase (COUTO et al., 2020; PRADO et al., 2018; SANTOS et al., 2019).

Essa omissão do sistema CONFEF/CREFs também pode ser observada na área da saúde, onde, apesar da prerrogativa legal para atuar na área desde 2002 (BRASIL, 1997; BRASIL 2002), consolidando-se com o passar do tempo (BRASIL, 2008), ainda existem secretarias municipais e estudais, como em Rondônia, que não incorporaram o profissional de EDF em sua tabela de Prestação de Serviços do Sistema Único de Saúde (SUS).

Nas entrevistas, a percepção de falta de representatividade e também de ação do conselho, no sentido de defender a profissão, foi recorrente. Destaca-se que o Estatuto do CONFEF, no momento em que se apresenta enquanto entidade, considera CONFEF e CREFs como "órgãos de normatização, disciplina, defesa e fiscalização dos profissionais de EDF, em prol da sociedade, atuando como órgãos consultivos do Governo" (Art. 2). Ainda considerando o mesmo documento, "divulgar a EDF, o profissional e o sistema CONFEF/CREFs" (Art. 5; item V), consta entre as finalidades do CONFEF; enquanto "zelar [...] pela valorização da profissão de EDF e de seus Profissionais" (Art. 26, item IV), está elencada como atribuição de competência do CONFEF. Assim, revela-se que é pertinente a compreensão dos docentes acerca desse assunto.

Identifica-se, na percepção dos entrevistados, a ânsia por uma gestão do CONFEF/CREFs verdadeiramente atuante, que seja mais envolvida com o profissional de EDF e com próprio futuro da profissão. Um sistema que de fato e de direito atenda as expectativas da categoria e cumpra com seu papel perante a sociedade.

Tschoeke (2017), destaca que a sociedade está em constante transformação evolutiva, na qual surgem diferentes formas de intervenção em cada profissão e novas profissões, fruto da complexidade das relações sociais, da própria evolução dos hábitos e modos de vida da população, bem como pelo enorme avanço e desenvolvimento tecnológico verificado nos últimos anos, os quais criaram novas necessidades. Em outras palavras, o mercado de trabalho, assim como a sociedade, é muito dinâmico e precisa estar sempre atento às mudanças que ocorrem ao seu redor. Profissões essenciais do passado foram gradativamente substituídas, razão pela qual se entende que ações mais efetivas do conselho de classe são fundamentais para o fortalecimento e garantia da existência da EDF no Brasil.

\section{Grupo 3: Apoiar, auxiliar e orientar os profissionais e as IES formadoras}


No terceiro grupo categorizado, a promoção de cursos e eventos destacou-se na fala dos entrevistados. Após a fiscalização, esta foi à atribuição mais citada dentre todas as categorias. Dez docentes a elencaram dentre as atribuições e oito como ações efetivas. Tal qual ocorreu para a atribuição de fiscalizar, acredita-se que a capacitação profissional continuada foi bastante citada pelo fato de ser uma ação concreta, realizada tradicionalmente pela seccional do CREF em Porto Velho, o que é confirmado na fala a seguir, que exemplifica essa situação.

[...] Eu tive a oportunidade, inclusive aqui na própria instituição, de assistir cursos que o Conselho Regional de Educação Física daqui de Rondônia trouxe para os profissionais e até mesmo para os acadêmicos. Então acho isso importante, acho que realmente tem que dar continuidade, até porque nós pagamos o conselho e talvez isso fosse interessante. Uma retribuição, digamos (Daiane).

De fato, no Estatuto do CONFEF, a capacitação profissional é entendida como atribuição do sistema. A confirmação desse disposto é encontrada no Art. 6, que descreve sobre as finalidades dos CREFs. No item VIII, está descrito como atribuição do CREF: “estimular, apoiar e promover o aperfeiçoamento, a especialização e a atualização de Profissionais de EDF registrados em sua área de abrangência".

A promoção de cursos e eventos revela-se uma ação muito positiva na visão dos docentes. Sobre os cinco docentes que relataram insatisfação com esta ação, o aspecto de insatisfação foi com a frequência/quantidade de realização $(n=2)$, com a baixa divulgação $(n=2)$ e com o fato de alguns cursos serem direcionados a instituições específicas e não abertos a todos $(n=1)$. Este resultado sugere que esta é uma ação que agrada os profissionais docentes e que deve ser intensificada.

Interessantemente, dentre os dez docentes entrevistados que entendem ser atribuição do sistema colaborar para o aprimoramento dos profissionais, cinco também entendem que é sua atribuição colaborar com as IES no processo de formação profissional.

Em publicação lançada pelo CONFEF, Steinhilber (2006, p.9), considera que é papel do CONFEF "zelar pela qualidade da formação profissional". No Estatuto do CONFEF, inclusive, identifica-se no Art. 46 dois órgãos permanentes de assessoramento dos CREFs, com atribuições que envolvem essa dimensão: a Comissão de Legislação e Normas e a Comissão de Ensino Superior e Preparação Profisssional. O Art. 53 desse documento detalha ainda as competências dessa última Comissão, destinada especificamente para essa finalidade.

Entende-se que a articulação do sistema CONFEF/CREFs com as IES é essencial e indispensável, não apenas para promover cursos e treinamentos, mas para colaborar com as discussões acerca do processo de formação dos futuros profissionais em EDF que atuarão no mercado de trabalho. Para reforçar esse argumento, cita-se Falci e Belisário (2013) e Lotti e 
Nakamura (2020), que descrevem sobre os desafios associados à formação em EDF na inserção desse profissional na área da saúde.

$\mathrm{Na}$ mesma linha de entendimento, as falas de alguns entrevistados revelam a opinião de que o conselho deveria estar mais presente nas instituições de formação profissional na área, também para esclarecer dúvidas existentes de acadêmicos e orientar para uma melhor visão e atuação no mercado de trabalho.

No campo da formação e, por conseguinte, intervenção profissional, embates entre o sistema CONFEF/CREFs e as IES, em função do distanciamento dessas organizações e também fruto de interpretações diferentes de Resoluções da Câmara de Educação Superior do Conselho Nacional de Educação (CNE/CES), marcaram a história recente da profissão e desgastaram relações interpessoais e interinstitucionais. Para entender esse fenômeno, Maia e Sarcado (2020), discorrem sobre as determinações históricas e implicações para formação e intervenção profissional, a partir da produção científica sobre as Diretrizes Curriculares para a Educação Física no Brasil.

Ainda sobre a questão da orientação, quatro docentes entendem que é atribuição do conselho orientar os profissionais. Assim como discutido anteriormente, essa atribuição (orientar) remete ao sentimento de reconhecer no órgão uma referência profissional. A falta de prestação de informações claras pelo sistema CONFEF/CREFs dificulta a atuação dos profissionais em seus campos de atuação/intervenção e gera incertezas na área de EDF.

Independentemente da forma, na análise das respostas, é possível identificar um ensejo em sentir-se mais próximos (em perspectiva) do sistema CONFEF/CREFs, com suas demandas devidamente atendidas. Espera-se que o órgão instrumentalize, sintetize e guie às ações profissionais, comuns a categoria, perante a sociedade. Destaque para Comissão de Orientação e Fiscalização, prevista no Estatuto do CONFEF, que dispõe, dentre outras coisas, dessa atribuição (Art. 35).

Outro aspecto que tem relação direta com o papel orientador do sistema é a divulgação de suas ações aos profissionais. É interessante notar que é neste quesito que está o segundo maior número de docentes insatisfeitos com o sistema CONFEF/CREFs $(n=6)$. Somente a fiscalização foi responsável por maior número de docentes insatisfeitos. Entende-se que esta realidade tem relação bastante próxima com a percepção de que o conselho, especialmente o CONFEF, está distante da classe por ele representada.

A divulgação do sistema, atualmente, ocorre por revista impressa e boletim por e-mail que é enviada pelo CONFEF, e não pelo CREF. Não está dentre as pretensões do presente trabalho verificar/comprovar se, de fato, esta é a única ação que o conselho profisssional em questão tem realizado. Interessa-nos, contudo, questionar e discutir a visão dos entrevistados sobre o assunto. 
Desta forma, apresenta-se uma fala que expressa possível justificativa para a quase inexistência de ações realizadas pelo CONFEF, na perspectiva dos docentes:

O CONFEF, ele fica lá em cima. Então ele não enxerga aqui em baixo e, principalmente, os CREFs que são mais distantes dele. Ele enxerga CREF região Sul e Centro-Oeste. [...] Então é meio complicado (Edite).

De acordo com os docentes entrevistados, a falta de interlocução entre os profissionais da Região Norte e o CONFEF é motivada pela distância (geográfica e política) entre os envolvidos. A fala anterior remete ao CONFEF. Em se tratando também do CREF local, dois docentes mostraramse insatisfeitos com a divulgação dos eventos. Portanto, considerando tal resultado, compreende-se que a divulgação é, na visão dos entrevistados, uma ação que precisa de ajustes por parte do sistema em questão. Falas de outra entrevistada são exemplificadoras dessa visão descontente e constam a seguir.

Os dois segmentos, CREF e CONFEF, eles somente nos procuram quando tem alguma obrigação que a gente tem que cumprir. [...] eles não vem até a gente (Emiliane).

(sobre eventos realizados na região) Nós não participamos em massa porque não houve divulgação, receberam e-mail algumas pessoas e outras não. Não há uma divulgação em massa do conselho, da instituição, pra que a gente consiga acessar o pouco que ele oferece (Emiliane).

A segunda fala apresentada anteriormente, além de expressar o descontentamento com a divulgação realizada pelo conselho, também retrata a percepção de que o conselho "pouco oferece" aos profissionais. Duas categorias de respostas relacionam-se com essa perspectiva: ausência de parcerias/convênios para os profissionais registrados no conselho $(n=1)$ e a expectativa de que o sistema CONFEF/CREFs colabore para um ambiente de trabalho adequado $(n=3)$.

A questão do oferecimento de benefícios pelo conselho é, ao mesmo tempo, uma reclamação frequente na classe de EDF e do próprio conselho. Este argumenta que não é seu papel oferecer benefícios aos profissionais, visto que o registrar-se é uma obrigação legal. Em contrapartida, mediante comparações com outros conselhos de classe, os profissionais argumentam que o sistema CONFEF/CREFs poderia fazer mais pela classe. Esta realidade foi encontrada em algumas falas:

A gente não tem um órgão que nos representa no sentido de garantir que a gente tenha uma boa estrutura de trabalho [...]. Aí diz assim: Ah! O CREF ele é um sindicato pra poder ver essas questões? Mas porque só a questão punitiva? Pra onde que vai o dinheiro que a gente investe? (Bianca)

Comparando com outras profissões, em relação a conselhos e sindicatos, tudo você vê que funciona. Por exemplo, um conselho de medicina, uma $\mathrm{OAB}$, você sabe que o cara faz e o conselho está em cima, sempre batendo na tecla, ajudando os 
profissionais. Então, assim, desejo muito que melhore com suas atribuições, instalações, tudo o que tiver que melhorar; da melhor forma (Lucas).

O nosso CREF está a desejar [...], minha irmã é formada em administração. Aí tem o conselho, por exemplo, ela paga, recebe lá as informações, a fiscalização [...]. O ano que ela deixou de pagá-lo chegou à notificação a nível federal, ela teve que responder no Fórum [...]. Ela tem convênio em lojas, academias, farmácias. O nosso CREF não oferece nada e é uma coisa tão fácil de fazer. Eu estaria satisfeito com isso (Eric).

Mendes (2014), comparou a atuação e a regulamentação do CONFEF com o Conselho Federal de Medicina (CFM), frente aos interesses de cada categoria. Segundo a autora, o CFM não só apresenta uma legislação mais abrangente, em benefício ao profissional Médico, como também assume uma postura mais eficiente e engajada na luta pelo profissional por ele representado. Dentre as pautas identificadas para esse argumento, destaca-se: a luta por mais verbas para a saúde; por uma gestão competente do SUS; por melhores salários para os médicos do serviço público; por honorários dignos para toda classe; pela regulamentação da profissão; por escolas médicas de qualidade e pelo aperfeiçoamento profissional continuado.

Sobre a expectativa de que o sistema CONFEF/CREFs colabore para um ambiente de trabalho adequado, inevitavelmente, passa outra vez pelo papel de fiscalização. Todavia, pela visão dos entrevistados a fiscalização realizada pelo CREF parece concentrar-se em torno do profissional - destaque para o fim punitivo - e não no seu ambiente trabalho. Igualmente, revela o entendimento de que trabalhar em prol da geração de ambientes de trabalho mais adequados ao profissional de EDF não está ligado ao sistema CONFEF/CREFs, mas sim aos sindicatos.

Apesar do Estatuto do CONFEF não descrever ações dessa natureza, assim como destaca uma das docentes, cuja fala consta acima, trata-se de uma iniciativa relativamente simples, hoje realizada por diversas categorias, que promovem um sentimento de pertencimento, união e valorização. Em consulta ao site do CREF8 constam parcerias existentes com cinco empresas que oferecem benefícios aos profissionais; todas localizadas, porém, na cidade de Manaus (CREF8, 2020).

Também ao encontro da percebida ausência de "benefícios" proporcionados pelo sistema CONFEF/CREFs aos profissionais, está à falta de ação - denominada por alguns de inércia - por parte do sistema.

A tabela 01 revela que as ações realizadas, em qualquer grupo, estão em número muito inferior ao que foi identificado como atribuições para mesma categoria. Ou seja, os docentes entrevistados retratam uma discrepância entre o que deve ser feito e o que de fato é realizado pelo sistema. 
A gente não vê ação nenhuma [...], a gente não vê nada, não tem ação nenhuma dentro do nosso estado (Eric).

Gostaria sim de expressar o descontentamento com a distância desses dois órgãos. O CONFEF, por ser federal parece ser uma instituição inacessível ao professor de educação física, profissional de educação física. E o CREF ele é distante. Temos a seccional aqui, mas como não fiscaliza e é distante a gente não vê a atuação (Emiliane).

Eu já vi enquanto eu era coordenadora de academia. O CREF vistoriava e fiscalizava. Mas fora isso, a não ser trazer curso de fora, eu não ouço falar de muitas ações do CREF. Realmente é algo meio que vazio que precisa melhorar (Daiane).

Uma das entrevistadas manifestou, inclusive, opinião de que as notícias da revista CONFEF, que divulgam ações de profissionais de EDF realizadas em regiões mais afastadas do país, conduzem a impressões equivocadas em relação às ações deste órgão. A partir dessa perspectiva, a entrevistada considera que faltam ações mais efetivas do sistema CONFEF/CREFs, o que se entende ser aplicável, especialmente a locais como o Estado de Rondônia, que está distante da sede do CONFEF no Rio de Janeiro.

$\mathrm{Na}$ tentativa de analisar integralmente o tema, entende-se que se entrelaçam as percepções referentes à falta de ações efetivas, a divulgação dessas e a distância percebida entre sistema e os profissionais. Ou seja, é possível que os docentes conheçam pouco as ações do sistema em virtude dessas não serem adequadamente divulgadas, o que conduz ao entendimento de que o sistema não realiza muitas ações práticas. Revelar se faltam ações efetivas ou se o que falta é divulgação está fora do escopo do trabalho e exige pesquisas futuras. Todavia, ressalta-se a visão coletiva de que melhorias precisam acontecer em diversas dimensões.

\section{CONSIDERAÇÕES FINAIS}

A percepção dos docentes de cursos de graduação em EDF de IES privadas da cidade de Porto Velho, a respeito das atribuições e ações do sistema CONFEF/CREFs, pode ser agrupada em três dimensões, que reunidas revelam a expectativa da categoria acerca desse sistema: a) regulamentar, organizar e fiscalizar; b) valorizar, representar e defender (profissão e profissional), perante a sociedade e c) apoiar auxiliar e orientar o profissional e as IES formadoras.

As categorias de atribuição e ação mais identificadas pelos docentes entrevistados foram a fiscalização e a capacitação profissional. Acredita-se que esse resultado seja influenciado pela própria forma de atuação/intervenção do sistema na região.

Conjuntamente, as análises revelam que os docentes das IES privadas de Porto Velho são conhecedores de grande parte das atribuições e competências do sistema CONFEF/CREFs. 
Todavia, no que diz respeito ao cumprimento dessas, ou seja, às ações, na perspectiva de todos os docentes o sistema em questão revela-se falho, especialmente na fiscalização dos profissionais, na divulgação de suas ações, na valorização, representação e defesa da profissão perante a sociedade.

Apesar de reconhecerem as dificuldades enfrentadas pelo sistema CONFEF/CREFs, os docentes entrevistados, em geral, encontram-se insatisfeitos com a atuação deste em pelo menos algum aspecto relacionado à gestão e operação, seja a nível local ou nacional.

Igualmente, os docentes entrevistados aprovam a existência do conselho. Porém, almejam um sistema que seja mais engajado com a defesa do profissional de EDF e que colabore para o exercício profissional consciente.

Considerando a importância do profissional de EDF na sociedade contemporânea, explorar os temas propostos nesse artigo contribui para melhor compreensão sobre a realidade regional, viabiliza a avaliação da situação atual e também a adoção de estratégias necessárias para aperfeiçoar a atuação e ação do sistema CONFEF/CREFs frente às suas competências institucionais.

Para estudos futuros sugerimos que outras regiões do país sejam pesquisadas, o que também é relevante que seja feito na cidade de Manaus, onde se localiza a sede do CREF8. Entende-se ainda que a visão dos profissionais de EDF que atuam diretamente no sistema CONFEF/CREFs precisa ser contemplada. No mesmo sentido, a voz dos profissionais de EDF que atuam diretamente nos cenários de prática (escolas, academias, clubes) deve ser ouvida. Acreditamos que somente através dessas informações a realidade poderá ser melhor compreendida, aumentando as chances que um caminho de diálogo possa ser de fato construído entre todos os sujeitos/instituições relacionados à atuação do sistema CONFEF/CREFs.

\section{REFERÊNCIAS}

ALMEIDA, Marco Bettine, MONTAGNER, Paulo César; GUTIERREZ, Gustavo Luis. A inserção da regulamentação da profissão na área de educação física, dez anos depois: embates, debates e perspectivas.

Revista Movimento, Porto Alegre, v. 15, n. 03, p. 275-292, jul./set., 2009, DOI: https://doi.org/10.22456/1982-8918.3051.

BRASIL. lei no 9.696, de 1 de setembro de 1998.Dispõe sobre a regulamentação da Profissão de Educação Física e cria os respectivos Conselho Federal e Conselhos Regionais de Educação Física. Diário Oficial da União, Brasília, 02 set. 1998.

BRASIL. Ministério da Educação/Conselho Nacional de Educação/Câmara de Educação Superior. Parecer n.138, de 3 de abril de 2002. Diretrizes Curriculares Nacionais do Curso de Graduação em Educação Física. Diário Oficial da União, Brasília, 26 abr. 2002.

BRASIL. Ministério da Educação/Conselho Nacional de Educação/Câmara de Educação Básica. Resolução n.07, de 14 de dezembro de 2010. Fixa Diretrizes Curriculares Nacionais para o Ensino Fundamental de 9 (nove) anos. Diário Oficial da União, Brasília, 15 de dezembro de 2010. 
BRASIL. Ministério da Saúde/Conselho Nacional de Saúde. Resolução n.218, de 6 de março de 1997. Reconhece profissões da área da saúde. Diário Oficial da União, Brasília, 06 mar. 1997.

BRASIL. Ministério da Saúde. Portaria n. 154, de 24 de janeiro de 2008. Cria os Núcleos de Apoio à Saúde da Família - NASF. Diário Oficial da União, Brasília, 24 jan. 2008.

CONFEF, Conselho Federal de Educação Física. Estatuto do Conselho Federal de Educação Física. Diário Oficial da União, Brasília, 13 dez. 2010.

COUTO, Josiene de Oliveira et al. What is the contribution of each physical activity domain to total physical activity in adolescents?. Revista Brasileira de Cineantropometria e Desempenho Humano, Florianópolis, v. 22, e70170, 2020, DOI: https://doi.org/10.1590/1980-0037.2020v22e70170.

CREF8, Conselho Regional de Educação Física da $8^{a}$ Região. Estatuto do CREF8/AM-AC-RO-RR. Disponível em: https://www.cref8.org.br/estatuto-do-conselho-regional-de-educacao-fisica-da-8a-regiao/. Acesso em 21 jul. 2020.

CREF8, Conselho Regional de Educação Física da 8a Região. História. Disponível em: https://www.cref8.org.br/galeria/. Acesso em 21 jul. 2020.

CREF8, Conselho Regional de Educação Física da $8^{\text {a }}$ Região. Parcerias. Disponível em: https://www.cref8.org.br/parcerias/. Acesso em 21 jul. 2020.

DE PAULA, Alisson Slider do Nascimento; SILVA, André Luis Façanha da. Contribuição à crítica à formação profissional e a divisão do trabalho na educação física: um estudo à luz da ontologia marxista. Boletim Gepep, São Paulo, v. 03, n. 05, p. 03-26, dez., 2014.

FALCI, Denise Mourão; BELISARIO, Soraya Almeida. A inserção do profissional de educação física na atenção primária à saúde e os desafios em sua formação. Interface (Botucatu), Botucatu, v. 17, n. 47, p. 885-899, dez., 2013, DOI: https://doi.org/10.1590/S1414-32832013005000027.

GUIATA, Nicole Roessle; SILVA, Marcelo Moraes. A regulamentação do profissional de Educação Física: um diálogo com Herbert Marcuse. Motrivivência, Florianópolis, n. 30, p. 217-230, dez., 2008, DOI: https://doi.org/10.5007/2175-8042.2008n30p217.

LOPES, Ivone Goulart. História da educação no Brasil: desafios e perspectivas. Atena: Curitiba, 2016.

LOPES, Gilson Junior Oliveira et al. Onde atuam, por que não atuam e o quão satisfeitos com o trabalho estão os licenciados em Educação Física?. Pensar a Prática, Goiânia, v. 23, p. 1-20, 2020,

DOI: https://doi.org/10.5216/rpp.v23.56700.

LOTTI, Alessandro Demel; NAKAMURA, Eunice. Significados da prática profissional em Educação Física na área da saúde. Pensar a Prática, Goiânia, v. 23, e54518, p.1-23, 2020.

DOI: https://doi.org/10.5216/rpp.v23.54518.

MAIA, Júlio César Apolinário; SACARDO, Michele Silva. A produção científica sobre as Diretrizes Curriculares para a Educação Física (DCNEF): determinações históricas e implicações para formação e intervenção profisssional. Movimento, Porto Alegre, v. 26, e26037, mai., 2020, DOI: https://doi.org/10.22456/1982-8918.97618.

MENDES, Alessandra Dias. Educação física: atuação profissional e condições de trabalho em academias. Orquestra: Porto Alegre, 2014.

MINAYO, Maria Cecília de Souza. O desafio do conhecimento: pesquisa qualitativa em saúde. 11 ed. São 
Paulo: HUCITEC, 2008.

NEIRA, Marcos Garcia; BORGES, Clayton Cesar de Oliveira. Esquadrinhar e Governar: análise das recomendações do CONFEF para a Educação Física escolar. Educação \& Realidade, Porto Alegre, v. 43, n. 2, p. 571-590, jun., 2018, DOI: http://dx.doi.org/10.1590/2175-623664150.

OLIVEIRA, Edson Eduardo Rodrigues de. A Importância da Regulamentação da Profissão de Educação Física para uma Categoria Profissional: O caso de Minas Gerais. Porto, 2017, 107 f. Dissertação (Mestrado em Gestão Desportiva). Faculdade de Desporto, Universidade do Porto, 2017.

PEREIRA, Aline Fraga et al. Satisfação de estudantes universitários de Educação Física com experiências acadêmicas. Motrivivência, Florianópolis, v. 30, n. 53, p. 84-100, abr., 2018, DOI:

https://doi.org/10.5007/2175-8042.2018v30n53p84.

PRADO, Crisley Vanessa et al. Physical activity opportunities in public and private schools from Curitiba, Brazil. Revista Brasileira de Cineantropometria e Desempenho Humano, Florianópolis, v. 20, n. 3, p. 290-299, mai., 2018, DOI: https://doi.org/10.5007/1980-0037.2018v20n3p290.

REPPOLD FILHO, Alberto Reinaldo. Código de ética profissional: considerações históricas e filosóficas. In: TOJAL, João Batista; COSTA, Lamartine Pereira Da; BERESFORD, Heron (org.). Ética Profissional na Educação Física. Shape: Rio de Janeiro, 2003, p.97-102.

SANTOS, Josivana Pontes dos et al. Fatores associados a não participação nas aulas de educação física escolar em adolescentes. Journal of Physical Education, Maringá, v. 30, e3028, 2019, DOI: http://dx.doi.org/10.4025/jphyseduc.v30i1.3028.

SILVA, Guilherme Gil da; FRIZZO, Giovanni Felipe Ernst. Crítica à regulamentação da profissão e à produção científica defensora do sistema CONFEF/CREFs. Motrivivência, Florianópolis, n. 36, p. 149-168, jan., 2011, DOI: https://doi.org/10.5007/2175-8042.2011v23n36p149.

SILVA, Marcelo Moraes; LANDIN, Renata Aparecida Alves. Os impactos da regulamentação da profissão de educação física na prática pedagógica. Revista do Mestrado em Educação, UFS, São Cristóvão, v. 7, p. 79-94, jul./dez., 2003.

SOBRINHO, José Pereira de Sousa et al. O sistema CONFEF/CREF e a reestruturação curricular dos cursos superiores de educação física: a formação do "profissional" (neo)liberal. In: XVII COBRACE e IV CONICE, Porto Alegre, 2011. Anais do XVII Congresso Brasileiro de Ciências do Esporte e IV Congresso Internacional de Ciências do Esporte. Disponível em: http://congressos.cbce.org.br/index.php/conbrace2011/2011/paper/view/2978. Acesso em: 21 jul. 2020.

STEINHILBER, Jorge. Sistema CONFEF/CREFs e a responsabilidade Ética. In: TOJAL, João Batista; BARBOSA, Alberto Puga (org.). A Ética e a Bioética na preparação e na intervenção do profissional de Educação Física. Casa da EducaçãoFísica: Belo Horizonte, 2006, p.7-15.

TOJAL, João Batista Andreotti Gomes. A carta brasileira de educação física. Revista Brasileira de Ciências do Esporte, Capinas, v. 23, n. 1, p. 79-85, set., 2001.

TSCHOEKE, Rony. A função pedagógica da comissão de ética profissional do sistema CONFEF/CREF'S. In. VARGAS, Ângelo (org.). Dimensionamento ético da intervenção profissional em Educação Física. 2017, 159 p. Disponível em:https://www.listasconfef.org.br/arquivos/publicacoes/dimensionamento etico angelo.pdf. Acesso em 26 jun. 2020. 


\section{NOTAS DE AUTOR}

AGRADECIMENTOS - Não se aplica.

CONTRIBUIÇÃO DE AUTORIA- Não se aplica.

FINANCIAMENTO- Não se aplica.

CONSENTIMENTO DE USO DE IMAGEM- Não se aplica.

APROVAÇÃO DE COMITÊ DE ÉTICA EM PESQUISA

Parecer consubstanciado de número 2.307.443.

CONFLITO DE INTERESSES - Não há conflitos.

\section{LICENÇA DE USO}

Os autores cedem à Motrivivência- ISSN 2175-8042 os direitos exclusivos de primeira publicação, com o trabalho simultaneamente licenciado sob a Licença CreativeCommonsAttribution NonComercial ShareAlike (CC BY-NC SA) 4.0 International. Esta licença permite que terceirosremixem, adaptem e criem a partir do trabalho publicado, desde que para fins não comerciais, atribuindo o devido crédito de autoria e publicação inicial neste periódico desde que adotem a mesma licença, compartilhar igual. Os autores têm autorização para assumir contratos adicionais separadamente, para distribuição não exclusiva da versão do trabalho publicada neste periódico (ex.: publicar em repositório institucional, em site pessoal, publicar uma tradução, ou como capítulo de livro), com reconhecimento de autoria e publicação inicial neste periódico, desde que para fins não comerciais e compartilhar com a mesma licença.

\section{PUBLISHER}

Universidade Federal de Santa Catarina. Programa de Pós-Graduação em Educação Física. LaboMídia - Laboratório e Observatório da Mídia Esportiva. Publicado no Portal de Periódicos UFSC. As ideias expressadas neste artigo são de responsabilidade de seus autores, não representando, necessariamente, a opinião dos editores ou da universidade.

\section{EDITORES}

Mauricio Roberto da Silva, Giovani De Lorenzi Pires, Rogério Santos Pereira.

\section{EDITOR DE SEÇÃO}

Juliano Silveira

\section{REVISÃO DO MANUSCRITO E METADADOS}

João Caetano Prates Rocha; Keli Barreto Santos

\section{HISTÓRICO}

Recebido em: 23 de julho de 2020

Aprovado em: 05 de setembro de 2020 